\title{
On the Variations of the Daily Mean Sea Levels along the Japanese Islands*
}

\section{Daitaro SHоJI**}

\begin{abstract}
The variations of the daily mean sea levels at 22 tide stations along the Japanese coast and their relations to the oceanographic and meteorological phenomena were examined. It was found that the variations are closely related to the oceanographic conditions, and that the coast of Japan may be divided into several distincts, in each of which the variations are similar, and in particular that characteristic high and low waters appear to move along the coast with velocities of internal wave.
\end{abstract}

\section{Introduction}

In the previous papers (SHoJI, 1954, 1955 and also S. Yoshida, 1961), it was shown, making use of the daily mean sea levels at the tidal stations on Hachijo-jima and others of the Izu peninsula, that the daily mean sea levels change parallel to the dynamic heights of the neighbouring seas and, there- fore, the variations of oceanographic conditions of the sea can be inferred from the data of the mean sea levels. Especially the variations of the axis of the Kuroshio is clearly indicated by the change of the sea levels of Hachijo-jima.

In this report the daily mean sea levels along the all coast of Japanese Islands are

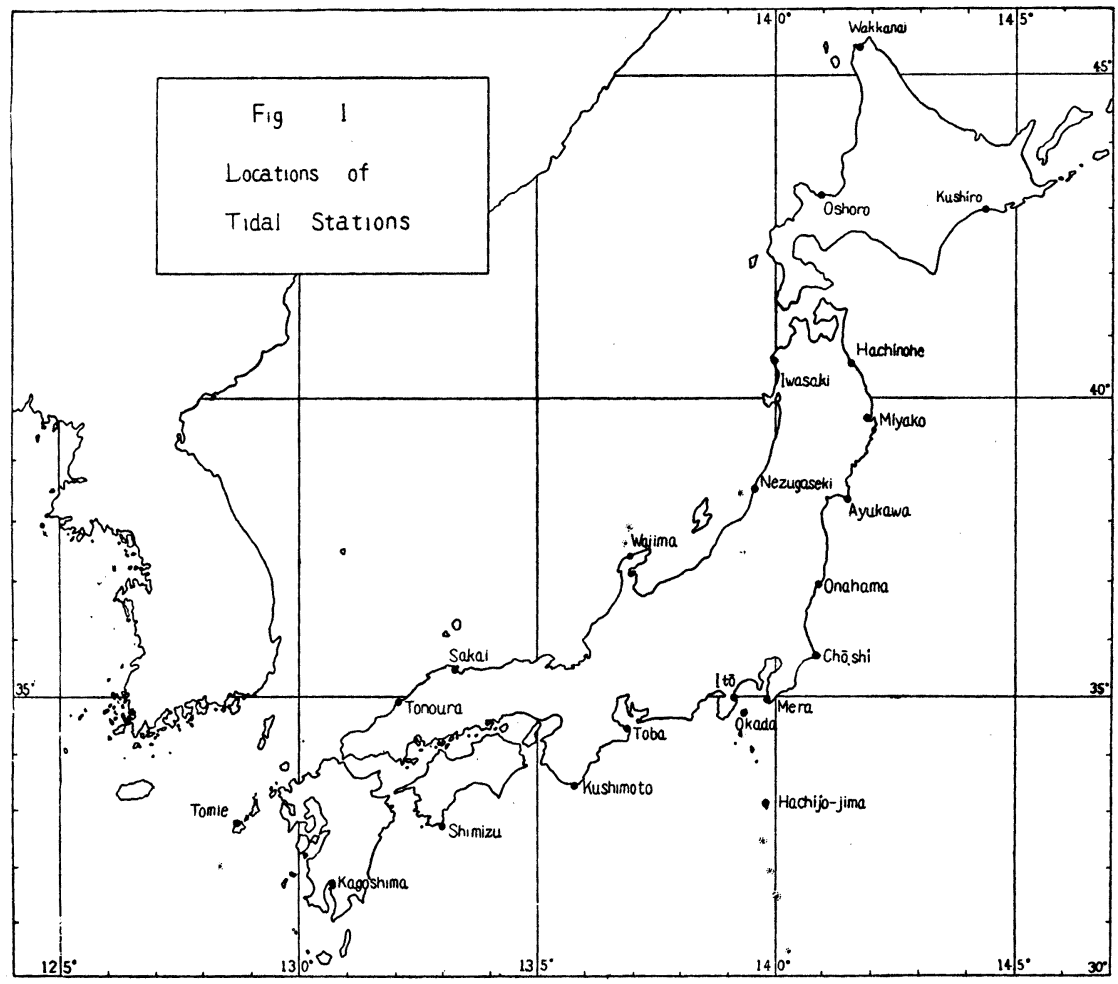

* Received June 6, 1961.

** Hydrographic Office of Japan. 
examined and the relations between sea levels and the oceanographic and meteorological conditions are tried to be found as far as possible. But the data of oceanographic observations are not so abundant as it is possible to be compared with the mean sea levels which can be obtained from day to day.

In this study the "mean sea level" means the 24-hour mean of the sea levels, corrected for the barometric effect, on the assumption that the atmospheric pressure of 1 millbar corresponds to 1 centimeter of the sea level, so that

$$
\text { " mean sea level" } l=h+p .
$$

where $h$ is the 24-hour mean of the sea levels from 0 to 23 o'clock of a day, in centimeter, $p$ is daily mean atmospheric pressure at the weather station nearest to each tidal station, in millibar. It will be better if we use 25-hour mean instead of the 24hour mean in order to eliminate the astronomical tides, but 24 -hour mean was adopted to save computations. And, because mean air pressure is the mean of 4 observations a day, it may have comparatively large errors, especially at the time of violent meteorological disturbances. The effect of the wind will be discussed later.

The locations of the tidal stations treated here are shown in Fig. 1. Among them three stations, Wajima, Nezugasaki and $\mathrm{O}$ shoro, belong to the Geographical Survey Institute and one, Hachijo to the Hydrographic Office and all the other stations to the Meteorological Agency.

\section{Variations along the Pacific Coast}

Figs. 2 and 3 show the variations of the daily mean sea levels along the Pacific coast of Japanese Islands from north to south. Fig. 2 is the one for 1955 and Fig. 3 for 1956 respectively. From these figures, the followings are readily seen.

a) At each station, there appear variations of period of days to tens of days, besides the annual variations which is high in summer and low in winter. However, these variations of shorter periods are not always smaller than the annual variations, and often reaches more than 20 centimeters, especially in southern areas.

It is well known that the annual variations are due to the seasonal variation of temperature of the upper water of the ocean and this is not the subject of this paper, but it may be remarked that the variations of very long period of the oceanic current may affect these annual variations. (Nomissu et al. 1927)

b) The variations at Hachijo-jima are much greater than that of other places and have different features. It was already explained in the previous papers that this is due to the variations of the axis of the Kuroshio.

c) It is easily seen that the Pacific coast is divided into two parts; north of Chosi and southwest of Mera. In northern part, the annual variations are predominant and in southern part the variations of shorter periods are very large.

By closer examination, the northern part may be further divided into Hokkaido coast and east coast of Honshu, and Kagoshima is a little different from other southern stations.

d) Characteristic features of the variations, for example, large crests and troughs can be traced throughout each area, some of them can be traced in all the Pacific coast. And these features seem to travel from north to south in general, contrary to the direction of the current of the Kuroshio.

These facts are explained as follows. The Japanese Islands are situated in the field of streams which may be called the Kuroshio current system and consists of the Kuroshio and the Tsushima current. The coast line of these islands is approximately the stream line of this stream field. As far as the currents are considred to be geostrophic and the vertical and horizontal frictions are neglected, the stream line coincide with the equipotential line. Therefore, the sea level along the coast should be nearly equal at all points. The island such a Hachijo-jima and Hokkaido, which is separated by a strait where a strong current exists, are on a different stream lines, so the sea levels can change independently. And the currents 


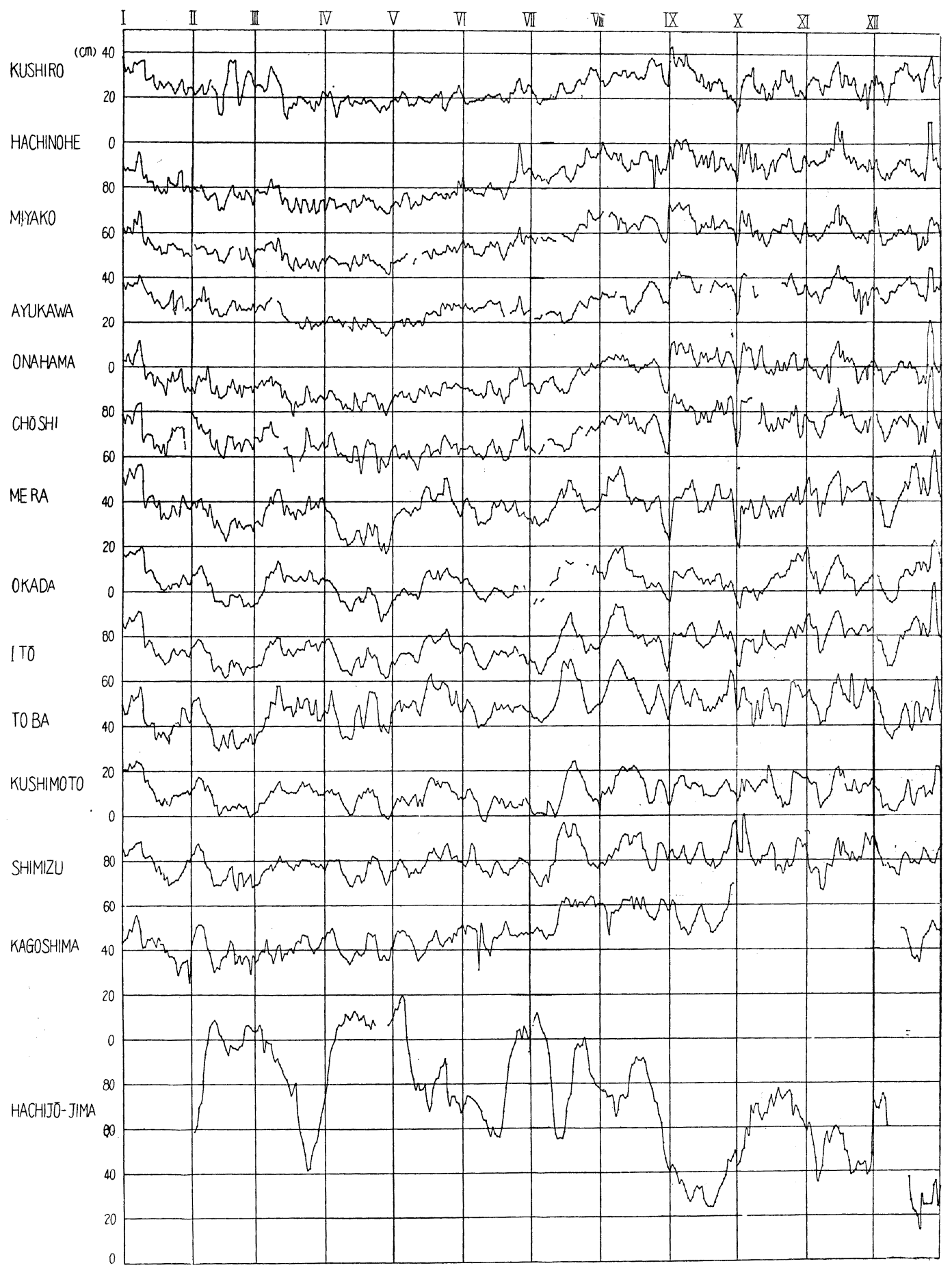

Fig. 2. The Variation of Daily Mean Sea Level 1955 (Pacific Coast). 


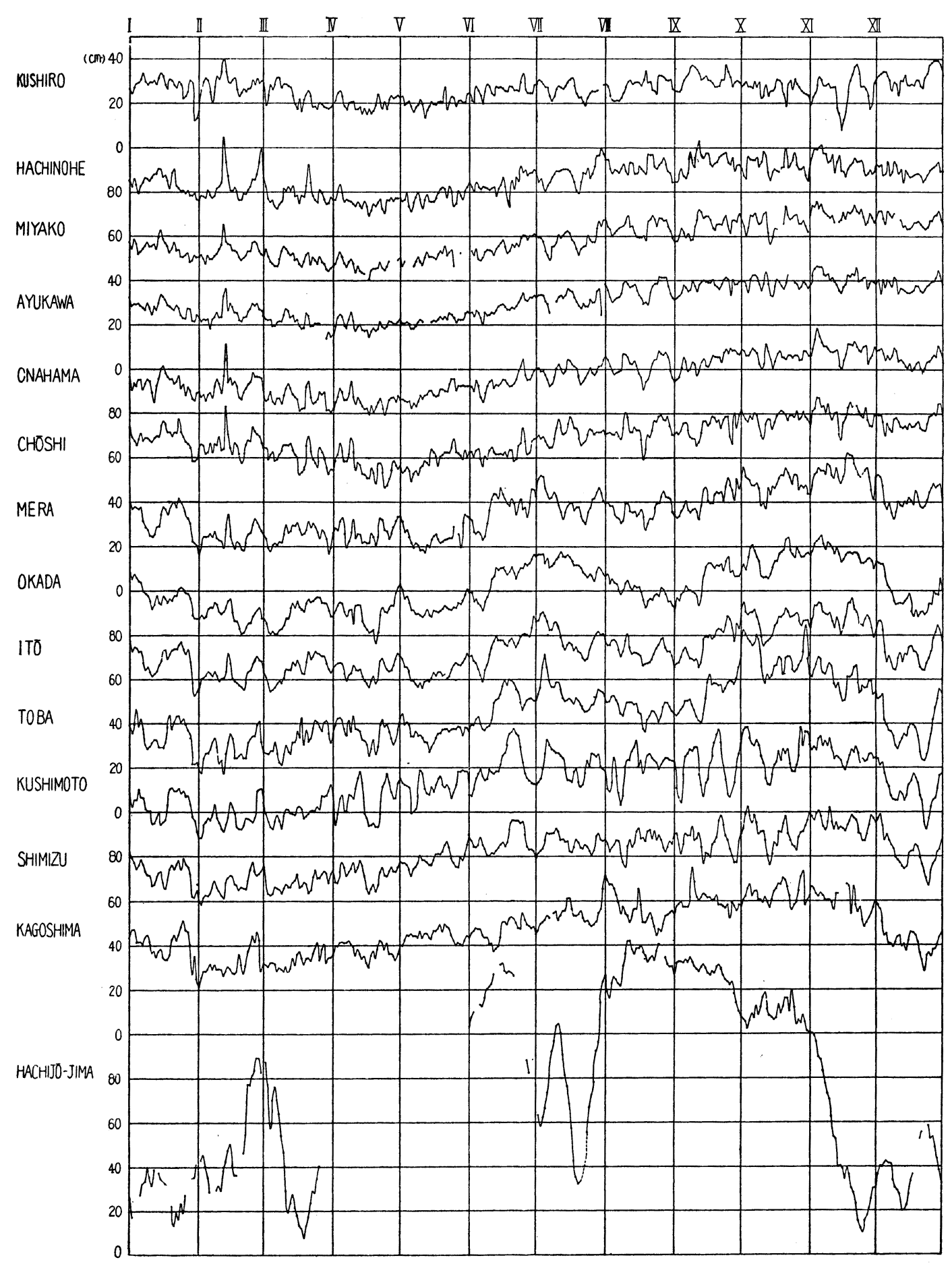

Fig. 3. The Variation of Daily Mean Sea Level 1956 (Pacific Coast). 
in the strait or between Hachijo-jima and the main land are related to the difference of sea levels on both sides by the equation of the geostrophic current. (Hikosaka, 1953 and S. Yoshida, ibid)

On the other hand, if the sea levels at two points on a same coast differ, there must be a current along coast between them. This current is not geostrophic. Assuming that the TorRICELLI's formula holds for this case as the first approximation, that is, velocity $v=\sqrt{2 g h}$, and taking $h=10 \mathrm{~cm}$., the velocity of the current is estimated to be about $150 \mathrm{~cm} / \mathrm{sec}$. As the direction of the current of this kind is same as the slope of the sea surface it will not be stable, except for some reason.

The fact that the type of the variation of mean sea levels differs between Mera and Choshi means that strong currents appears frequently in this area and this corresponds well to the fact that the Kuroshio flows always near coast in this area. And the report of MorIYASU that the difference of monthly sea levels between Kushimoto and Uragami (10 miles east of Kushimoto) is closely related to the location of the Kuroshio off this coast is considered to be of the same nature. (Moriyasu, 1958) Hence, it will be possible to know the meandering of the Kuroshio by taking the differences of sea levels at a suitable pair of tidal stations.

According to the charts of the distribution of sea water temperatures in the ocean around Japan, there always exists a warm water along the east coast of Honshu which come down from the Tsugaru strait between Honshu and Hokkaido. This is also explained from the principle that along the coast the water level has to remain as constant as possible.

\section{Sea Level Variations along the South Coast Japan}

The variations of sea levels along the south coast of Japan are much greater than along the east coast of Honshu, as mentioned above. In this area, the strong current of the Kuroshio flows near the coast, and these variations are considered to be an expression of the variations of the Kuroshio.

Across the Kuroshio, the sea surface has a slope and the difference of the sea levels between left and right side of the current reaches about 100 centimeters. The sea level of right-hand (off-shore) side may be assumed to make little variations of short periods, so when the sea level along the coast rise the difference of sea level between both side become smaller, and the current become weaker, and vice versa. The amplitude of the variations is often 20 to 30 centimeters and is 20 to 30 per cent of the total difference.

In the vicinity of Mera and Choshi, when the sea level along the south coast rises, the sea level at Mera will rise, too, but at Choshi the sea level will remain unchanged relatively, and the difference between them increases. The current along this coast will also increase. We get a little paradoxical conclusion that when the Kuroshio become weaker the current of this coast and neighboring sea become stronger. These inference are to be confirmed by the actual oceanographic observations.

As pointed out in the previous papers, the sea levels along the south coast of Honshu and at Hachijo-jima tend to change inversely. The falling of sea level at Hachijo means the south-eastward movement of the cold water mass off Enshu-nada. Therefore, it may be concluded that the weakening of the Kuroshio accompanies the south-eastern translation of the cold water mass.

All these considerations are applied only to the variations which can be traced throughout the all south coast. Besides them there are local variations, too. For example, in the record of Kushimoto in 1956, there appeared a crest on 21st Sept. and a trough on 26 th of the same month, and the difference between them was as large as 30 centimeters. This crest and trough could be seen at Shimizu, too, but were not clear in the eastern area from Toba. In this month, three typhoons came to Japan and this crest and trough might be due to these typhoons. (9th, 22nd, and 27th of Sept.) But it seems certain that this phenomenon was not due 
to the simple wind effect. The actual variations of the Kuroshio or the density distributions were not clear owing to the lack of the observations.

On 30th Oct., 1956 there was a high peak on the record of Toba. This peak was certainly caused by run-off due to the heavy rain fall on the nearby land area.

A regular oceanographic observation began in 1955 , as a joint operation of the Japanese Hydrographic Office and Meteorological Agency. But it has been carried out on a quarterly basis and quite inadequate to be compared with the variations of mean sea levels. Nevertheless, it is not in vain to look at the general features of the Kuroshio in these period. In 1955, there was a cold water mass continuousely off the south coast of Japan. In earlier half of the year the cold water mass was in relatively western part and during autumn and spring of 1956, it moved to eastwards and became smaller. By the observation of May, 1956, it was found that it almost disappeared but in June it appeared again for a short period and in August and October the cold water mass did not exist. In November, 1956, the sea level of Hachijo-jima fell and indicated that the cold water mass again appeared in this area. (See "the State of the Adjacent Seas of Japan" issued quarterly by the Hydrographic Office of Japan.)

As seen above, the sea levels at Hachijojima correspond well with the behavior of the cold water mass (in other words, the position of the Kuroshio in this area), but the sea level along the coast of Honshu seems to have little relations with it. More detailed examinations are needed.

\section{Sea Level Variations caused by Storm Surges}

Compared with the sea level variations along the south coast, it is more simple and monotonous along the east coast of Honshu and this is due to the fact that there is no strong currents off these coast.

But a few remarkable variations were found on this coast. From 26th to 30th, Dec. 1955 and 12th to 15th, Feb. 1956, there were high crests on all the stations on the Pacific coast. The times of the maxima of these crests were estimated from a figure (Table 1, unit of time; $\frac{1}{4}$ of a day), and plotted in Fig. 4 (left half).

According to the Geophysical Review of the Japanese Meteorological Agency, a severe storm hit the east coast of Honshu on 26th of December, 1955, (Fig. 5) and many coastal constructions suffered from great damages by high water due to this storm, especially in the vicinity of Miyako. Also, on 12th, Feb. 1956, a storm hit Miyako and Hachinohe, due to a depression, passed off this coast.

In either case, there occurred a high water due to the strong wind and then the disturbance travelled southwards along the coast of Japan. Its velocity is about $250 \mathrm{~cm} / \mathrm{sec}$ outside of the originating area, from Fig. 4. The next table shows the observed wind excerpted from the Geophysical Review. In both case, strong northerly winds blew for more than 24 hours. It is worth to note that the wind directions were north, rather than

Table 1

\begin{tabular}{c|c|c|c|c|c|c}
\hline Station & Kushiro & Hachinohe & Miyako & Ayukawa & Onahama & Choshi \\
\hline Dec. & 27 & $26 \frac{1}{2}$ & $26 \frac{1}{2}$ & $26 \frac{1}{2}$ & $26 \frac{1}{4}$ & $26_{4}^{\frac{3}{4}}$ \\
Feb. & 12 & 12 & $12 \frac{1}{4}$ & $12 \frac{13}{3}$ & 13 & $13 \frac{1}{4}$ \\
\hline Station & Mera & Ito & Toba & Kushimoto & Shimizu & \\
\hline Dec. & $27 \frac{1}{2}$ & $27 \frac{3}{4}$ & 29 & $29 \frac{1}{2}$ & 31 & \\
Feb. & $13_{\frac{3}{4}}$ & $14 \frac{1}{2}$ & $15 \frac{1}{2}$ & $15 \frac{1}{2}$ & - & \\
\hline
\end{tabular}




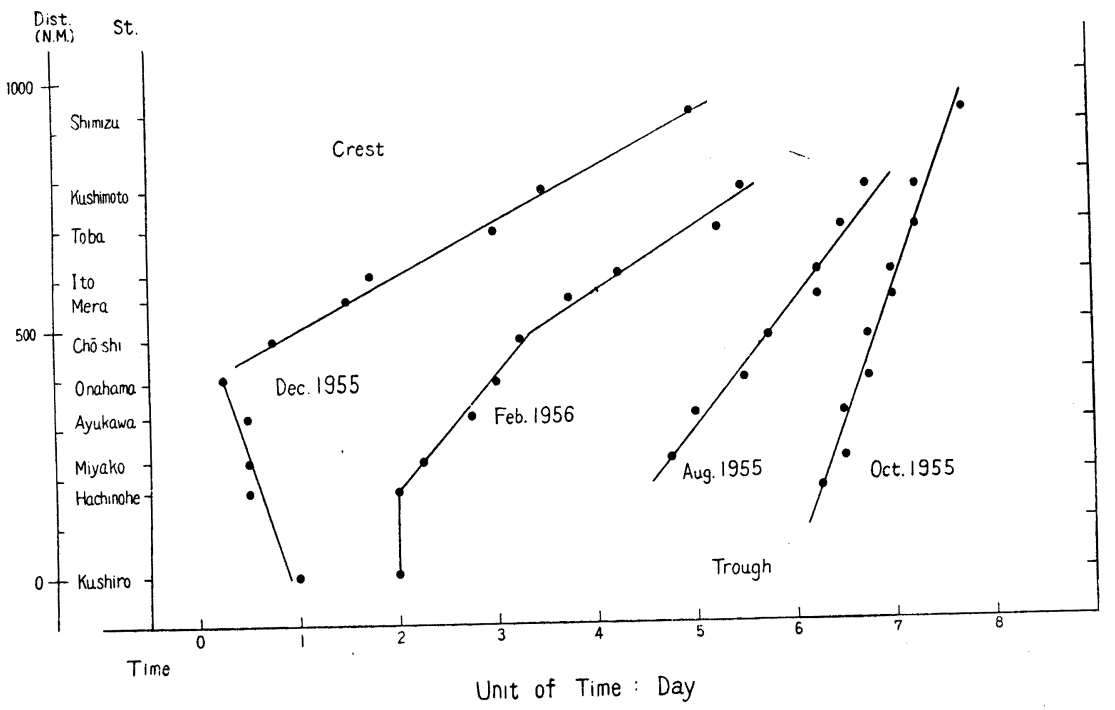

Fig. 4. Travel Time Diagram.

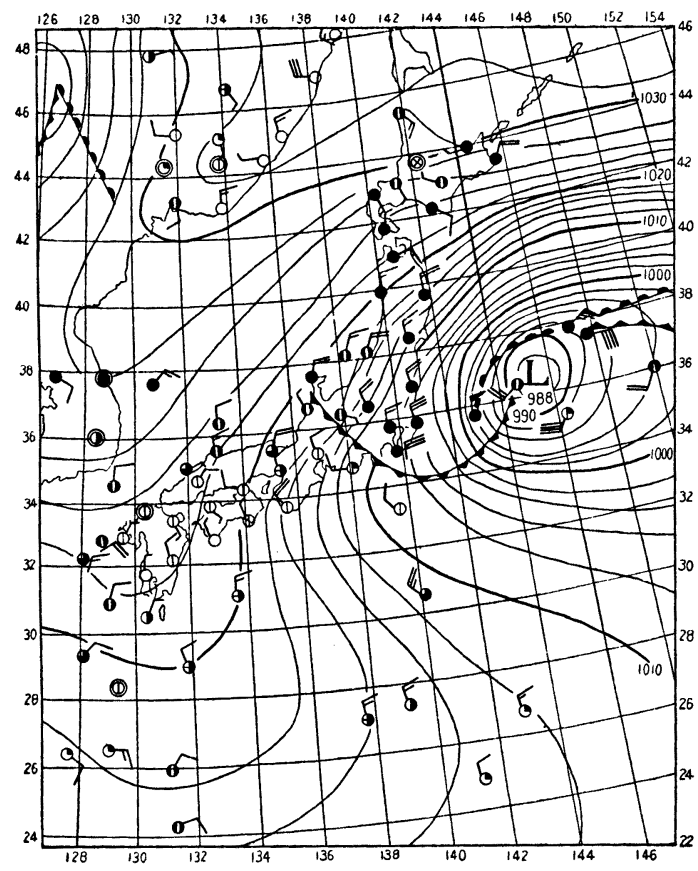

Fig. 5. Weather Map at 0900 (J.S.T.) December 26th, 1955.

east.

According to the records of Hachinohe, there were surges on 26th June, 1955, 29th, Feb. and 21st, Mar. 1956 and in every case the winds were northerly, but the high waters did not travel to the south. The conditions which determine whether a storm surge in this area is transmitted or not, are not clear. They will be related to the direction of wind, area in which the surge occurs and the oceanographic conditions at that time and so on.

At the end of August and the beginning of October, 1955, there appeared deep troughs along the Pacific coast of Japan. The time of minimum for each station was calculated and plotted in the same manner as above and tabulated below. And the right half of Fig. 4 shows the result. From this figure the velocity of travel of these troughs are determined as about $550 \mathrm{~cm} / \mathrm{sec}$ and $700 \mathrm{~cm} /$ sec, respectively.

According to the Review mentioned above, strong southerly wind blew between Miyako and Choshi from 29th to 31st of August, due to the front activity of the depression No. 17 of that month. And at the end of September the typhoon No. 22 passed through the Japan Sea, and again southerly winds were very strong along this coast on 30th Sept. and 1st Oct. (Fig. 6) Therefore, these lowering of sea level are the results of the weather conditions that strong southerly winds blow parallel to the coast and is just the counterpart of the above mentioned highwater. 
Table 2 .

\begin{tabular}{|c|c|c|c|c|}
\hline & Station & Max. wind vel. $(\mathrm{m} / \mathrm{sec})$ & Wind dir. & Time \\
\hline \multirow[t]{4}{*}{ Dec. } & Choshi & 28.5 & NNW & $\begin{array}{ccc}\mathrm{d}_{26} & \mathrm{~h} & \mathrm{~m} \\
26 & \end{array}$ \\
\hline & Onahama & 16.9 & $\mathrm{~N}$ & 260345 \\
\hline & Miyako & 13.2 & $\mathrm{~N}$ & $2611 \quad 10$ \\
\hline & Hachinohe & 23.5 & ENE & 260050 \\
\hline \multirow[t]{3}{*}{ Feb. } & Choshi & 19.3 & $\mathrm{~N}$ & 122350 \\
\hline & Miyako & 13.5 & $\mathrm{~N}$ & 120950 \\
\hline & Hachinohe & 25.5 & $\mathrm{~N}$ & 120630 \\
\hline
\end{tabular}

Table 3 .

\begin{tabular}{c|c|c|c|c|c|c}
\hline Station & Hachinohe & Miyako & Ayukawa & Onahama & Choshi \\
\hline $\begin{array}{l}\text { Aug. } \\
\text { Oct. }\end{array}$ & $\begin{array}{c}30 \frac{3}{4} \\
\text { (Sept.) }\end{array}$ & 1 & 30 & $30 \frac{1}{2}$ & $30 \frac{3}{4}$ \\
\hline Station & Mera. & Ito & Toba & Kushimoto & Shimizu \\
\hline Aug. & $31_{\frac{1}{4}}^{\frac{1}{4}}$ & $31 \frac{1}{\frac{1}{4}}$ & $31 \frac{1}{2}$ & $31_{\frac{3}{4}}$ & - \\
Oct. & $1 \frac{1}{2}$ & $1 \frac{1}{2}$ & $1 \frac{3}{4}$ & $1 \frac{3}{4}$ & $2 \frac{1}{4}$ \\
\hline
\end{tabular}

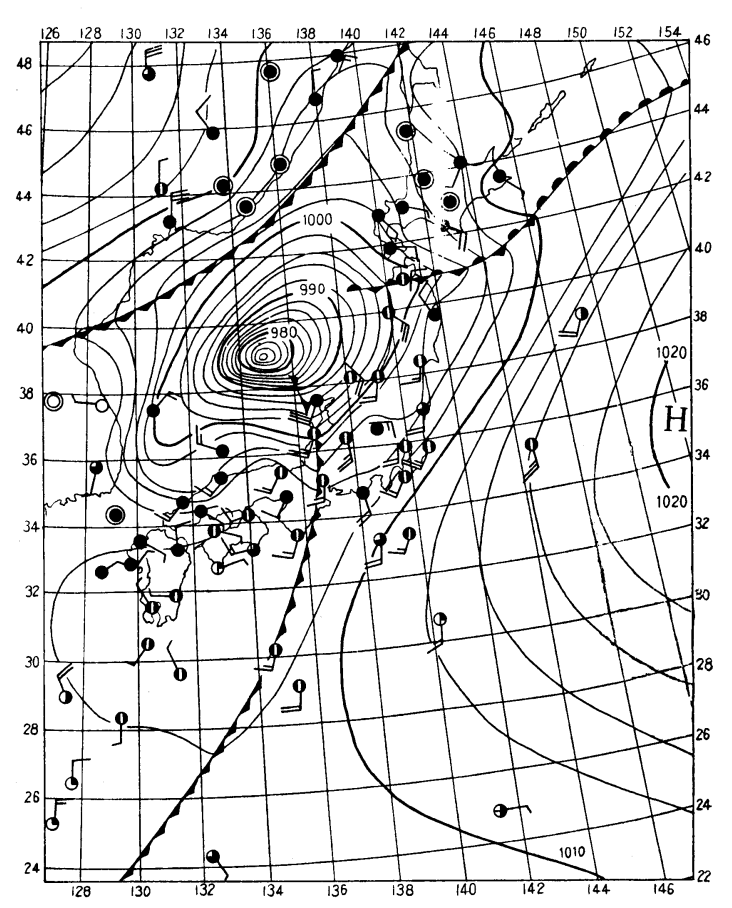

Fig. 6. Weather Map at 2100 (J.S.T.) September 30th, 1955.
According to K. Yoshida, (K. Yoshida, 1960) the phenomenon that a sea level disturbance travels along the coast may be interpreted as an internal Kelvin wave (Proudman, 1953). Its velocity is given by

$$
c=\sqrt{g \Delta \rho} \sqrt{H \cdot H^{\prime} / D},
$$

where $c$ is the velocity, $g$ acceleration of the gravity, $\Delta \rho$ the difference of density between lower and upper layer (sea is considered to consist of two layers of water). And $H$ and $H^{\prime}$ are the thickness of lower and upper layer respectively, and $D$ is the total depth. Assuming that $g=1000 \mathrm{~cm} / \mathrm{sec}^{2}$ $\Delta \rho=2 \cdot 10^{-3}, \mathrm{D}=4000 \mathrm{~m}=4 \cdot 10^{5} \mathrm{~cm}$, and taking $c=250 \mathrm{~cm} / \mathrm{sec}, \mathrm{H}^{\prime}$ (thickness of the upper layer) is estimated as about $350 \mathrm{~m}$. This value is plausible. But the velocity of the troughs, $500 \mathrm{~cm} / \mathrm{sec}$ or more, is a little too large to be explained by this formula. However, considering that the effect of upwelling can reach deeper than heaving, and hence $\Delta \rho$ and $H^{\prime}$ can be greater it is conceivable that the velocity of the troughs is larger than that of the crests.

Intense sinking or upwelling of water or 
strong currents are supposed to accompany with these travelling disturbances, but there are no observations which give evidences of them.

\section{Sea Level Variations along the Japan Sea Coast}

Figs. 7 and 8 show the variations of the daily mean sea levels along the Japan Sea coast of Honshu and Hokkaido, together with the west coast of Kyushu. From these figures, one can see easily the characteristics of this coasts. a) The variations along the Japan Sea coast show much larger day to day variations when compared with that of the Pacific coast or the west coast of Kyushu, and have quite different features. The range of variations often reaches to $30-40$ centimeters in a few days.

b) Remarkable crests or troughs occur almost simultaneousely throughout this coast or one day later in northern part than in southern part.

c) The variations at Tomie and Kagoshima are very similar with each other, and smooth

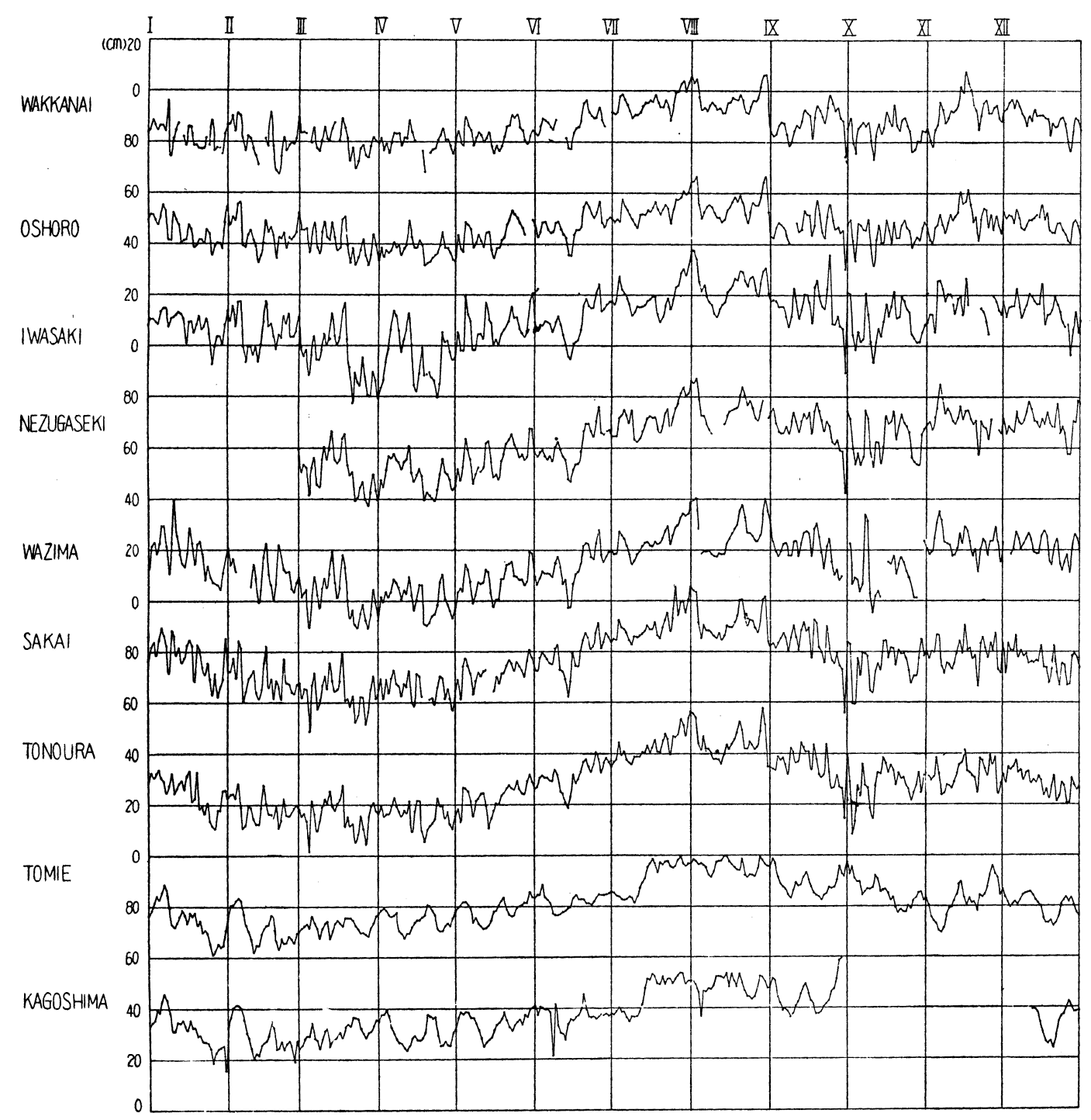

Fig. 7. The Variation of Daily Mean Sea Level 1955 (Japan Sea Coast). 
as the Pacific coast but their shapes are differ from that of the Pacific coast.

It is certain that the large variations of sea levels along the Japan Sea coast are mainly due to the action of winds, because all remarkable crests or troughs are always accompanied by strong winds of typhoons, fronts or monsoons. The west or southwestern winds cause to rise and north or northeastern winds to lower the sea levels.

But it is an another question why the wind effect is much larger along the Japan Sea coast than the other coast, and more detail- ed considerations are necessary.

The barometric coefficient is approximately equal to 1 , according to a rough estimation, and it is same as the other coast.

The shallowness of the Japan Sea (especially in south-western part) and the topographical features of the sea (an independent sea bounded by lands) may be pointed out as the causes of this phenomenon. But along the west coast of Kyushu and the Okhotsk coast of Hokkaido, both shallow as the southwest Japan Sea, the sea level fluctuations are not so large as this, and therefore,

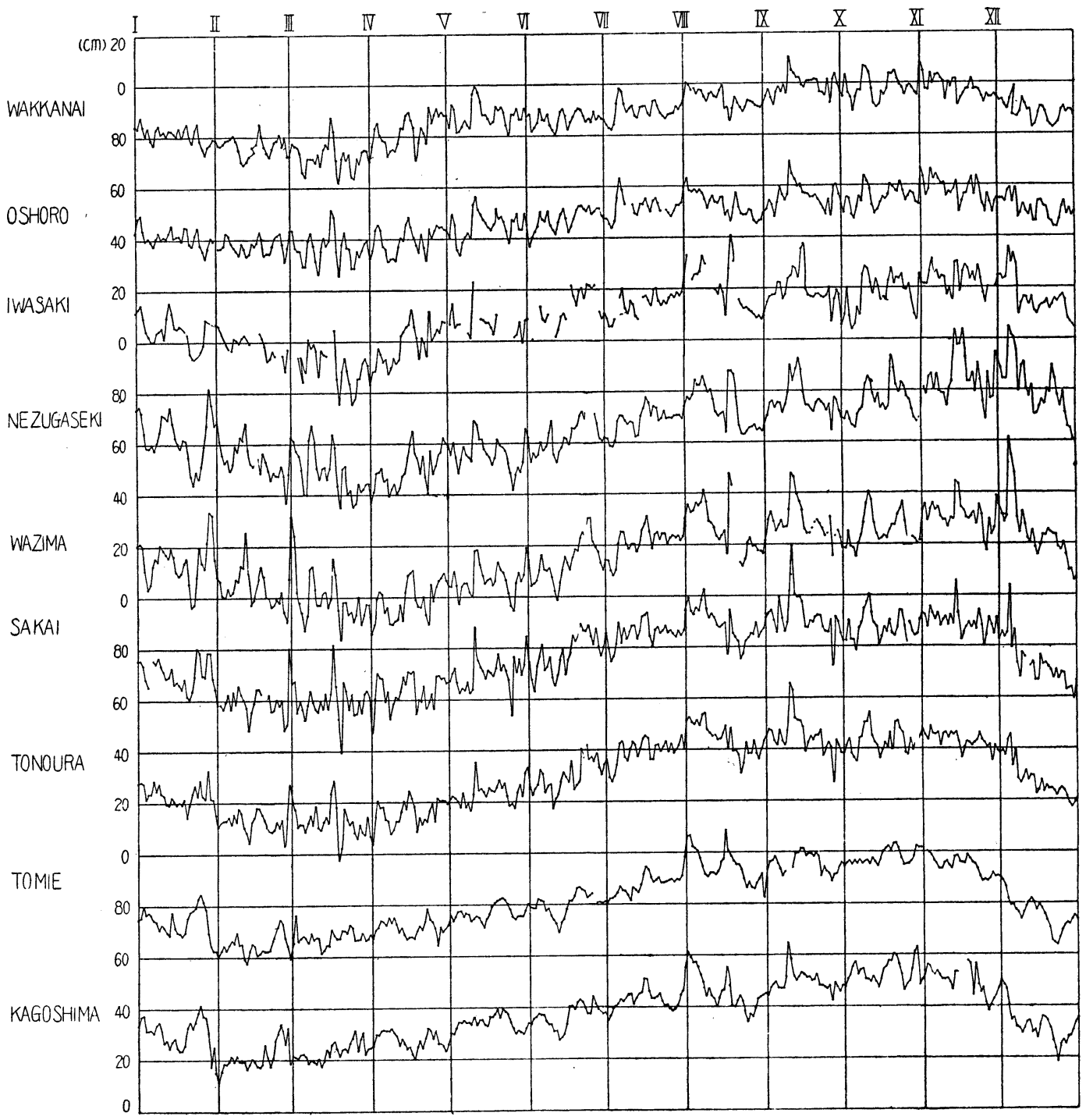

Fig. 8. The Variation of Daily Mean Sea Level 1956 (Japan Sea Coast). 
shallowness is difficult to be the main reason.

According to the paper of $\mathrm{K}$. Yoshida, mentioned above, the internal Kelvin wave proceed from south to north along the coast, which is situated on east side of a sea as the Japan Sea coast, contrary to the Pacific coast. And the meteorological disturbances such as depressions or typhoons generally proceed from south to north in this area, so the direction of the Kelvin wave and its meteorological cause have a common direction of travelling. Therefore, a resonance effect of some kind may occur in this case. The velocity of depressions is usually 10 to $20 \mathrm{~m} / \mathrm{sec}$ and the velocity of the Kelvin wave is estimated to be about 5 to $10 \mathrm{~m} / \mathrm{sec}$, and the sea level fluctuation moves with a velocity of $10 \mathrm{~m} / \mathrm{sec}$ or more.

As another characteristic of the Japan Sea, off the coast of Honshu in the Japan Sea warm water mass of $200-300$ meters thick lies above the cold and uniform Japan Sea deep water, and a sharp transition layer always exists between them. This may have relation with the rapid variation of Japan Sea coast, for example as internal seiches.

At present, no definite answer can be given to this problem. The first step for solving this problem will be to determine by observation whether the condition of the static equilibrium is satisfied or not in the Japan Sea, as it has been proven in the Pacific Ocean.

The sea level of the west coast of Kyushu has to relate closely with the current through the Tsushima strait between Korea and Japan, and hence with the sea level variations in the Japan Sea, too. But the relations between them are not clear from Figs. 5 and 6 , because of large fluctuations along the Japan Sea coast.

The difference between the types of variation along the coast of Kyushu and the south coast of Japan will be related to the current of the Osumi strait, south of Kyushu, where the Kuroshio runs over a shallow ridge and the Tsushima current separate from the Kuroshio.

\section{Conclusions}

Summarizing the above, followings are the main conclusions of this paper.

a) The coast of the Japanese Islands is divided into the following areas by the type of variations of daily mean sea levels, and in each area the sea level variations are very similar for all stations; the south coast of Hokkaido, east coast of Honshu, west coast of Kyushu, Japan Sea coast (and Okhotsk coast of Hokkaido).

And this division can be interpreted in connection with the distribution of oceanic current around the Japanese Islands.

b) The variations of daily mean sea levels along the south coast of Honshu are closely related to the variation of the Kuroshio. From the variation of sea levels, it is inferred that the Kuroshio make large variations in a few days. It seems there are no definite periods for them.

c) Along the Pacific coast, the variations of sea level travel from north to south along the coast, especially it was found that high and low waters due to the winds were transmitted with velocities of $250 \mathrm{~cm} / \mathrm{sec}$ to $700 \mathrm{~cm} / \mathrm{sec}$ and this phenomenon was explained as internal Kelvin wave.

d) The daily mean sea levels along the Japan Sea coast are greatly affected by winds and it is suggested that the internal Kelvin wave may be essential as a secondary cause.

Besides these conclusions, it will be worth to note that along the Pacific coast the direct wind effect is hardly to be observed except on a few occasions. In the two years under examination many typhoons came to Japan, nevertheless, no remarkable high water was observed at the day of hitting. It will be said that this indicate winds affect primarily to change the density distribution of the sea and this means that the so-called response time is rather short in the ocean.

In this report only qualitative descriptions and considerations concerning the variations of daily mean sea level were given. More detailed and quantitative investigations are necessary by means of actual observations as well as theoretical studies. We have 
very few observations, such as the one described by S. YoshidA, already mentioned, which can be compared with the day to day variations of sea level.

\section{Acknowledgement}

The author express his deep appreciations to Mr. R. Watanabe, Mr. S. Yoshida and Miss K. Tamura who helped him in computations and preparations of the manuscript.

\section{References}

HIKoSAKA, S., 1953:

On the Ocean-current (Non-tidal Current) in the Tsugaru Strait. (in Japanese.) Hydrographic Bulletin, 39, 1953.

MORIYASU, S., 1958:

On the Fluctuation of the Kuroshio South of Honshu (4). Journ. Oceanogr. Soc. Japan. 14, (4), 1958.

Nomitsu et al., 1927:

The Causes of Annual Variation of the Mean
Sea Level Along the Japanese Coast. Mem. Coll. Sci. Kyoto Univ. Ser. A, 10, 1927.

Proudman, J., 1952:

Dynamic Oceanography. Methuen, London, 1952.

SHOJI, D., 1954:

On the Variation of Daily Mean Sea Level and the Oceanographic Condition. (in Japanese) Hydrographic Bulletin, Sp. No. 14, 1954.

SHoJI, D., 1955:

On the Variations of Daily Mean Sea Levels and the Kuroshio from 1954 to 1955. Proc. Unesco Symp. Phys. Oceanography, Tokyo. 1955.

YoshidA, K., 1960:

The Oceanic Waves of Days to Months' Periods. Rec. Oceanogr. Works, Japan. 5, (2), 1960.

YoshidA, S., 1961:

On the Short Period Variation of the Kuroshio in the Adjacent Sea of Izu Islands. (in Japanese) Hydrographic Bulletin, 65, 1961. 